\title{
Linear and Nonlinear Seismic Structural Impact Response Spectral Analyses
}

\author{
J. Geoffrey Chase ${ }^{1, *}$, Florent Boyer ${ }^{2}$, Geoffrey W. Rodgers', \\ Gregoire Labrosse ${ }^{3}$ and Gregory A. MacRae ${ }^{4}$ \\ ${ }^{1}$ Dept of Mechanical Engineering, University of Canterbury, Christchurch, New Zealand \\ ${ }^{2}$ ENSMA, Futuroscope Chasseneuil, France \\ ${ }^{3}$ ISTIL, Lyon, France \\ ${ }^{4}$ Dept of Civil and Natural Resources Engineering, University of Canterbury, Christchurch, New Zealand
}

(Received: 10 April 2014; Received revised form 18 August 2014; Accepted: 20 October 2014)

\begin{abstract}
This paper describes analyses of single-degree-of-freedom structures with different spacing, coefficients of restitution, structural periods, and both linear and nonlinear cases, to a suite of earthquake records with equivalent probability of occurrence. A methodology to relate the probability of impact, and the probability of different levels of percentage peak, spectral displacement increase over a suite of events with equivalent probability of occurrence. Thus, both analyses provide a design risk assessed for these different design parameters, which provides a framework for risk analysis and design that is developed and illustrated. It is shown that smaller gaps between structures and greater difference between structural periods independently lead to greater probabilities of impact. Also, smaller gaps, greater coefficients of restitution and structural linearity (i.e. less yielding) lead to increases of structural displacement as a result of impact. The overall results provide significant insight into the design parameters and their sensitivity around structural impact, and provide these results within a risk based framework amenable to designers and the profession. The approach developed may be generalized to other cases with more degrees of freedom, different masses or damping values.
\end{abstract}

Key words: structural dynamics, impact, pounding, spectral analysis, probability, linear, nonlinear, stereo-mechanics.

\section{INTRODUCTION}

Earthquake-induced structural pounding and impact occur when two nearly placed structures have a large enough response to induce collide. In highly urbanized areas, distances between adjacent buildings can become quite small due to a lack of space, urban growth and infill or poor planning. This proximity can lead to impacts between structures during seismic events, leading to unexpected or additional damage. This phenomenon played a major role in some of the significant damage observed in Mexico in 1985 and Kobe in 1995, and is often not directly considered in design so that the resulting increases in demand lead to potentially significant added damage.

A similar issue occurs in bridges, such as in Prince William Sound, Alaska, in 1964, where the "Million Dollar" truss bridge collapsed during an earthquake. For bridges, impact occurs because the expansion joints allowing relative displacement between bridge sections can be too narrow, leading to collision that induces further demand and damage. Thus, bridge decks are another area of potential seismic impact that is often not directly considered in design. 
Typically, design guidelines are used to avoid impact, and thus do not consider it explicitly. There have been specific studies to investigate damage due to pounding for existing buildings and specific situations (Rosenblueth 1986; Scholl 1989; Kasai 1997; Jankowski, Wilde et al. 2000; Raheem 2006; Jankowski 2007a; Raheem 2009; Mahmoud, Abd-Elhamed et al. 2013; Raheem 2014). These reports highlighted the importance of adequate design for weaker buildings for which structural pounding can produce catastrophic damage. Thus, the problem has been identified. In addition, spectral analysis and spectral focused studies of adjacent structures (Chau and Wei 2001; Kin 2001; Lin 2002; Chau et al. 2003; Jankowski 2006; Raheem 2014) identified the period ratio of adjacent structures as an important parameter, affecting pounding risk. However, there are several other critical factors not accounted for in these studies. In particular, the building materials affect impact in terms of the energy lost and resulting coefficient of restitution. Equally, the linearity or nonlinearity of the structure plays a role both in the likelihood of impact as well as the resulting post-impact displacement. Finally, the main question remains unanswered, which is specifically the likelihood of an increase in displacement demand more than a specific value for structures at a specific distance subject to specific shaking. This answer to this question would provide significant new understanding and help begin answering how directly impact must be considered in structural designs for urban buildings and bridges, as well as for what specific cases.

Stereo-mechanical models based on conservation of momentum and assumed or known coefficients of restitution have been utilized to analyse and resolve pounding issues (Papadrakakis et al. 1991; Conoscente 1992; Chau and Wei 2001) and this method is used in this work. Others ways to conceptualize the collision include linear spring models (Maison 1990; Trochalakis 1997), and nonlinear finite element or analytical models (Chau and Wei 2001; Jankowski 2005; Raheem 2009; Jankowski 2012). However, these models cannot account for nonlinear energy loss. Other modeling approaches include a Kelvin model (Anagnostopoulos 1988), Hertz contact model (Pantelidesa 1998; Muthukumar 2006; Ye 2009) and a Hertzcamp model (Ye 2009), which are based, respectively, on a damping ratio dependant on the coefficient of restitution, a nonlinear spring of stiffness and a conjunction of a nonlinear spring and damping. Hence, there have been no complete analysis models presented that are simple enough for repeated use in understanding these dynamics well enough to create acceptable spectral analyses and design guidelines.
This research presents a complete, yet simplified, model system. It analyses the spectral displacement response for a suite of design level events considering structural periods, coefficient of restitution, gap between the structures, and linearity/nonlinearity of the structure. Outcome metrics include the probability of impact, and the resulting normalized median and $90^{\text {th }}$ percentile spectral displacement responses across a range of these design factors. No prior analysis has presented a complete analysis across all these factors, which limits understanding to more specific cases and doesn't provide the necessary range of results to understand the critical cases or create more general design guidelines.

\section{METHODS}

\subsection{Linear Model and Basic Model Structure}

Two single-degree-of-freedom (SDOF) oscillators are used to model generic nearby structures, as shown in Figure 1. The oscillators are decoupled with their own mass, stiffness and damping, but have the same mass to ensure equal seismic forces and simplify comparison. Thus, impact can only occur between the structures at the floor or, analogously, the bridge deck level (Cole, Dhakal et al. 2011). Seismic accelerations at the base of each oscillator are assumed to be the same because they are located very close to each other (Lig Seismic response of two span scale bridge model due to non-uniform ground excitation and varying subsoil conditions).

Equations of motion for the two independent single degree of freedom models when no impact occurs $\left(\mathrm{x}_{1}<\mathrm{x}_{2}+\lambda\right)$ are decoupled and defined:

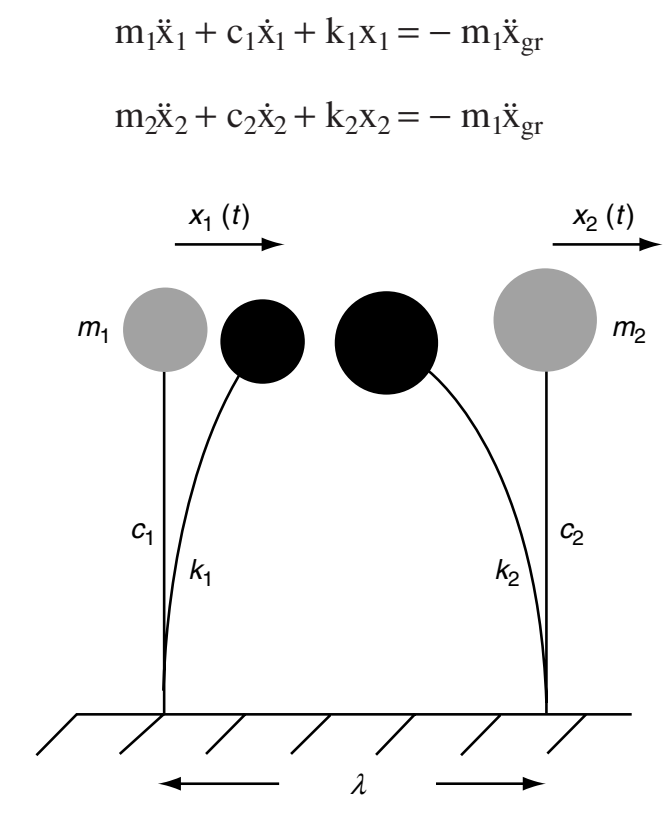

Figure 1. Fundamental model structure and linear model used for the impact study 
where $\mathrm{x}_{1}$ and $\mathrm{x}_{2}$ are the displacements of the oscillators, $\mathrm{k}_{1}$ and $\mathrm{k}_{2}$ are their stiffness, $\mathrm{m}_{1}$ and $\mathrm{m}_{2}$ their mass, $\mathrm{c}_{1}$ and $c_{2}$ their damping, $\ddot{x}_{\mathrm{gr}}$ is the ground acceleration, and $\lambda$ is the gap, where these variables are also shown in Figure 1.

\subsection{Modeling Impact}

Impact occurs when the two masses touch and $\mathrm{x}_{1}=\mathrm{x}_{2}+$ $\lambda$. The amount of dissipated energy is quantified within a coefficient of restitution, $e$, which is equal to 1.0 when the collision is fully elastic (no energy dissipated), and 0.0 when the collision is fully plastic (all the energy is dissipated). In reality, the value of $e$ is sensitive to the prior-impact velocity and tends to a range between 0.6 and 0.8 (Jankowski 2007b; Jankowski 2010).

Conservation of momentum before, during and after impact enables calculation of post-impact oscillator velocities based on the well-known derivation of Goldsmith (Goldsmith 2002):

$$
\begin{aligned}
& \dot{\mathrm{x}}_{1}^{\prime}=\dot{\mathrm{x}}_{1}-(1+\mathrm{e}) \frac{\mathrm{m}_{2}}{\mathrm{~m}_{1}+\mathrm{m}_{2}}\left(\dot{\mathrm{x}}_{1}-\dot{\mathrm{x}}_{2}\right) \\
& \dot{\mathrm{x}}_{2}^{\prime}=\dot{\mathrm{x}}_{2}+(1+\mathrm{e}) \frac{\mathrm{m}_{1}}{\mathrm{~m}_{1}+\mathrm{m}_{2}}\left(\dot{\mathrm{x}}_{1}-\dot{\mathrm{x}}_{2}\right)
\end{aligned}
$$

where $\dot{\mathrm{x}}_{1}$ and $\dot{\mathrm{x}}_{2}$ are the velocities before impact, and $\dot{\mathrm{x}}_{1}{ }^{\prime}$ and $\dot{\mathrm{x}}_{2}{ }^{\prime}$ are the velocities just after impact. Appendix 1 at the end of the article summarizes, briefly, this derivation.

To model behavior during impact, an equivalent impulse force $\mathrm{F}$ is introduced to Eqn 1 as an external load that is applied during one time step. This force is defined by Newton's Law as the discrete change in momentum over time (right hand side), which may be approximated for simulation, as:

$$
\mathrm{F}_{i}=\frac{\mathrm{m}\left(\dot{\mathrm{x}}_{i}^{\prime}-\dot{\mathrm{x}}_{i}\right)}{\mathrm{dt}}
$$

where $\mathrm{i}=1,2$. Note that $\mathrm{F}$ in Eqn 3 appiled to both masses, and there is thus an $\mathrm{F}_{1}$ and $\mathrm{F}_{2}$ defined this way. Hence, the equations of motion are coupled only when impact occurs, and are defined:

$$
\begin{aligned}
& \mathrm{m}_{1} \ddot{\mathrm{x}}_{1}+\mathrm{c}_{1} \dot{\mathrm{x}}_{1}+\mathrm{k}_{1} \mathrm{x}_{1}=-\mathrm{m}_{1} \ddot{\mathrm{x}}_{\mathrm{gr}}+\mathrm{F}_{1} \\
& \mathrm{~m}_{2} \ddot{\mathrm{x}}_{2}+\mathrm{c}_{2} \dot{\mathrm{x}}_{2}+\mathrm{k}_{2} \mathrm{x}_{2}=-\mathrm{m}_{2} \ddot{\mathrm{x}}_{\mathrm{gr}}+\mathrm{F}_{2}
\end{aligned}
$$

The gap ratio, GR, is a value defined in this work to normalize the gap between oscillator masses to the two oscillators spectral displacements, generalizing the analysis presented here to a very wide range of structures, as it is based on values, spectral displacements, well-known to designers.

$$
\mathrm{GR}=\frac{\lambda}{\mathrm{Sd}_{1}+\mathrm{Sd}_{2}}
$$

Spectral displacements, $\mathrm{Sd}_{1}$ and $\mathrm{Sd}_{1}$, are the maximum absolute displacements of the uncoupled structures for a given ground motion input without impact. Thus, impact may only occur if GR $<1.0$, and the two systems are independent otherwise. Therefore, all else equal, the probability of impact increases as the gap ratio decreases toward $\mathrm{GR}=0.0$ when the structures are touching at rest.

\subsection{Nonlinear Model}

To include column yielding in the analysis, the wellaccepted Ramberg-Osgood non-linear model is used (Ramberg 1943). It leads to a new definition of effective column stiffness and force:

$$
\begin{aligned}
& \mathrm{K}(\mathrm{i})=\mathrm{k}_{0} \frac{1}{\left(1+\mathrm{r} *\left(\frac{\mathrm{f}(\mathrm{i}-1)-\mathrm{f}_{\text {reset }}}{\operatorname{sign}(\dot{\mathrm{x}}(\mathrm{i})) * \mathrm{f}_{\mathrm{y}}-\mathrm{f}_{\text {reset }}}\right)^{\mathrm{r}-1}\right.} \\
& \mathrm{f}_{\text {col }}(\mathrm{i})=\mathrm{f}_{\text {col }}(\mathrm{i}-1)+\mathrm{K}(\mathrm{i}) *(\mathrm{x}(\mathrm{i})-\mathrm{x}(\mathrm{i}-1))
\end{aligned}
$$

where $f_{\text {reset }}$ is the value of column force, $f_{\text {col }}$, at the last reset point, when the sign of $\dot{x}$ changed, $f_{y}$ is the yielding force, $r$ is a constant, usually a large number, that controls the abruptness of stiffness loss, as shown in Figure 2, and $\mathrm{K}$ is the effective stiffness defined in Eqn 6 with nominal value $\mathrm{k}_{0}$. In this study $\mathrm{r}=50$ is used for $\mathrm{Kx}<3 \%$ post-yield stiffness.

\subsection{Solution and Simulation Methods}

The Newmark- $\beta$ method is used for solving all equations of motion, with $=0.25$. For the linear case, when impact occurs the external load is defined in Eqn 8 where $\mathrm{F}$ is defined in Eqn 3.

$$
\mathrm{F}_{\mathrm{ext}}=-\mathrm{m} \ddot{\mathrm{x}}_{\mathrm{gr}}+\mathrm{F}
$$

For the non-linear case, the linear restoring force, $\mathrm{kx}$, is set to $3 \%$ using $r=50$, and $\mathrm{f}_{\text {col }}$, defined in Eqn 7, is added as an external force, capturing linear and nonlinear restoring force behavior, yielding: 


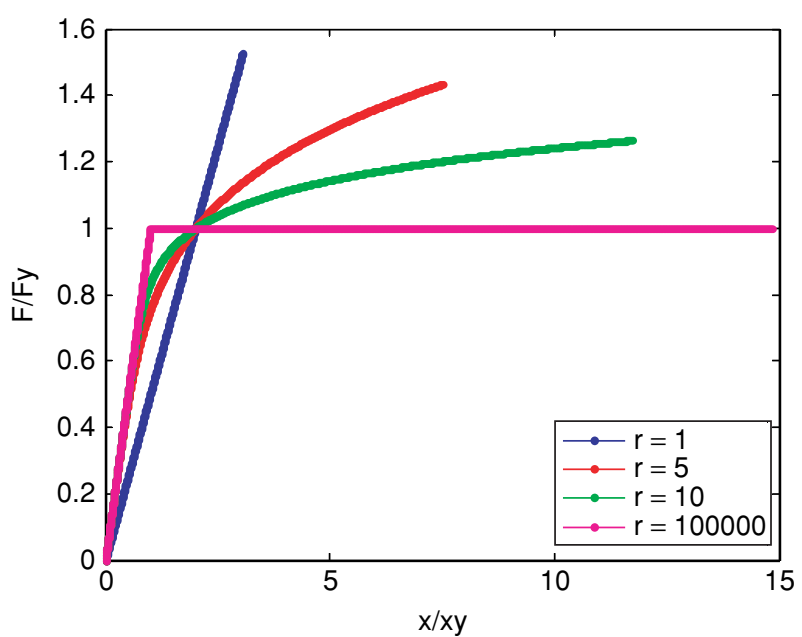

Figure 2. Imensionless Force-Displacement response nonlinear of a SDOF Ramberg-Osgood oscillator as a function of $r$ in the nonlinear model used (sinusoidal input with amplitude of $15, \mathrm{~m}=$ $1000 \mathrm{~kg}$, fy $=980 \mathrm{~kg}, \mathrm{~T}=5.0 \mathrm{~s}$, damping ratio $=0.05$ )

$$
\begin{aligned}
& \mathrm{m}_{1} \ddot{\mathrm{X}}_{1}+\mathrm{c}_{1} \dot{\mathrm{x}}_{1}=-\mathrm{m}_{1} \ddot{\mathrm{x}}_{\mathrm{gr}}+\mathrm{f}_{\mathrm{col} 1} \\
& \mathrm{~m}_{2} \ddot{\mathrm{x}}_{2}+\mathrm{c}_{2} \dot{\mathrm{x}}_{2}=-\mathrm{m}_{2} \ddot{\mathrm{X}}_{\mathrm{gr}}+\mathrm{f}_{\mathrm{col} 2}
\end{aligned}
$$

An inner iteration is required to solve $\mathrm{f}_{\text {col }}$ iteratively and ensure conservation of force, using Eqns 6 to 7, within each time step, as $f_{\text {col }}$ is a function of the displacement.

A time step $\mathrm{dt}=0.001 \mathrm{~s}$ is chosen based on a convergence analyses to ensure that impact in Eqn 3 was captured effectively.

\subsection{Earthquake Records}

The earthquake records utilized are a subset from the three suites from the SAC Steel Project in Los Angeles (Sommerville et al. 1997). The low, medium and high suites represent ground motions having probabilities of exceedance of 50\% in 50 years, $10 \%$ in 50 years and 2\% in 50 years. Hence, these suites represent equally likely events spanning a range of likelihood of occurrence, and thus a range of magnitudes. In this study, only the medium suite of design level events is used to ensure yielding of columns and relevance for design guidelines. Each record was run in both directions to remove directional effects, thus eliminating any effect of which order the two oscillating structures of Figure 1 are placed, and resulting in 40 simulations for the entire suite.

\subsection{Analyses}

\subsubsection{Design factors and inputs}

To analyze the effect of inelasticity in impact $(e)$ and inelasticity of columns $\left(f_{\text {col }}\right)$, this study is conducted with $\mathrm{m}_{1}=\mathrm{m}_{2}=1000 \mathrm{~kg}, \mathrm{f}_{\mathrm{y}}=980 \mathrm{~N}$ for each mass, a damping ratio $\xi=0.05$, and then varying several parameters. Specifically, the analysis factors considered are:

- Coefficient of restitution: $\mathrm{e}=0.4,0.6,0.8,1.0$, covering the full reasonable range, a somewhat larger level of energy loss $(e=0.4)$ and the perfectly elastic limit case $(\mathrm{e}=1.0)$.

- $\quad$ Structural period: $\mathrm{T}=0.2,0.5,0.8,1.0,3.0$ and 5.0 seconds, obtained by varying stiffness $\mathrm{k}$ in Eqn 1 and $\mathrm{k}_{0}$ in Eqn 9, for the elastic and inelastic cases respectively, which serves to ensure the seismic load the same for both structures for simplicity.

- Gap ratio: $\mathrm{GR}=0.2,0.5,0.8$ and 0.9 , which spans a reasonable range (Eqn 5).

Analyses are run with linear models covering all these combinations. For the non-linear model only e $=0.4,1.0$ are used to reduce computation and enable comparison over the range to the linear case.

\subsubsection{Performance metrics}

Displacement and design risk in this study focuses primarily on displacement changes, defined for each oscillator as the relative deviation between spectral displacement (maximum possible displacement in an event) with possible impacts, $\mathrm{Sd}$, and spectral displacement without impact (two independent systems), $\mathrm{Sd}_{\mathrm{ni}}$, where spectral displacements are wellknown and described as a design tool by Chopra (Chopra 1995). This value is thus defined as a relative or normalized displacement change factor, where values less than 0.0 indicate a reduction in displacement demand from the no-impact case and those greater than 0.0 indicate an increase. The displacement change factor (DCF) is thus defined:

$$
\mathrm{DCF}=\frac{\mathrm{Sd}-\mathrm{Sd}_{\mathrm{ni}}}{\mathrm{Sd}_{\mathrm{ni}}}
$$

The following metrics are calculated for each oscillator over all 40 records in the suite:

- Probability of at least one impact

- Median and $90^{\text {th }}$ percentile spectral displacement response DCF per Eqn 10.

These metrics thus assess the probability of impact, and the risk that the resulting peak displacement demands will be greater than the standalone structure which represents the design demand.

Thus, DCF $>0.0$ values at either level (median or $90^{\text {th }}$ percentile) indicate cases where the design limits are exceeded and additional demand is imposed on top of 
the added damage due to impact. Thus, these cases would carry significant added risk and need to be identified in terms of design values such as period (T), coefficient of restitution (e) and gap ratio (GR). The level (median or $90^{\text {th }}$ percentile) at which a DCF $>0.0$ value occurs provides an indication of the relative risk. Importantly, values of DCF $>1.0$ indicate an increase of $100 \%$ in displacement demand. All values were rounded to two decimal places.

Results are presented as tables in terms of oscillator periods $\left(T_{1}\right.$ and $\left.T_{2}\right)$ for a given GR and value of e. The tables are shown for both oscillators when presenting the probability of at least one impact. However, these tables are symmetric about the diagonal, due to earthquakes being analyzed in both directions. Thus, since each earthquake is simulated in both directions, results for one pair of periods are the same when the periods are transposed, which is the same as the table for the other oscillator's results. Thus, only the results for Oscillator 1 are presented, for reasons of space and clarity, for the spectral displacement response DCF data.

\section{RESULTS AND DISCUSSION}

\subsection{Displacement and Impact}

Figure 3 presents the displacement of both oscillators and impulse forces over time with 2 different values of $\mathrm{e}$, for the linear and non-linear case, and for one earthquake in the suite (LA10). It may be noted that the displacement magnitude for the oscillator with the higher period is greater than for the other oscillator, and for both of them it is larger for the higher value of e, where less energy is dissipated during impact. For the non-linear case, the displacements of both oscillators do not tend to 0 , because column yielding induces plastic deformation. In contrast, more impacts occur for the linear case and larger values of e.

\subsection{Probability of Impact}

Table 1 shows the probability, as a decimal value, of at least one impact in both the linear and the non-linear case for all GR values. There is no impact when the periods are the same $\left(T_{1}=T_{2}\right)$, because the oscillators move in phase, noting that different damping levels would affect this outcome. In general, the probability of impact increases as GR decreases, as expected. Note that for $\mathrm{GR}=0.2$, in the linear case, impact always occurs because the two structures are so close. Compared to the linear case, the probability of impact is lower in the non-linear case because column yielding dissipates energy and tends to make the oscillators act more in-phase. Even a high yielding force, and much reduced inelastic response, is sufficient to show measurable differences between the elastic and inelastic cases.
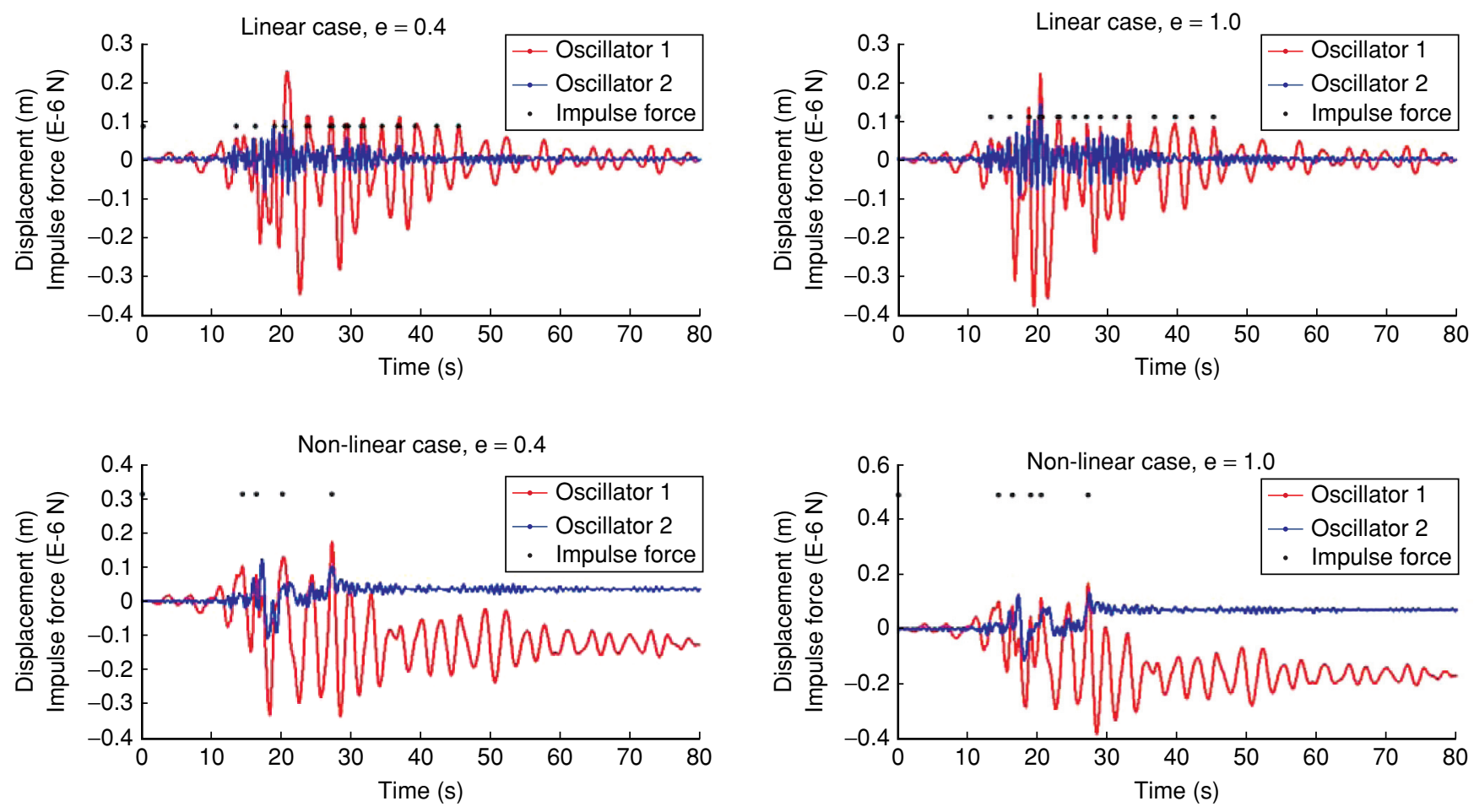

Figure 3. Displacement response $\left(\mathrm{LA} 10, \mathrm{~T}_{1}=3 \mathrm{~s}, \mathrm{~T}_{2}=0.8 \mathrm{~s}, \mathrm{e}=(0.4,1.0)\right.$, linear and non-linear cases) 
Table 1. Probability of at least one impact (elastic columns (left), inelastic columns (right), gap ratios $=(0.2,0.5,0.8,0.9), m_{1}=m_{2}=1000 \mathrm{~kg}, \xi=0.05,20$ earthquake records in the middle suite in both direction, $\mathrm{dt}=0.001 \mathrm{~s}$ )

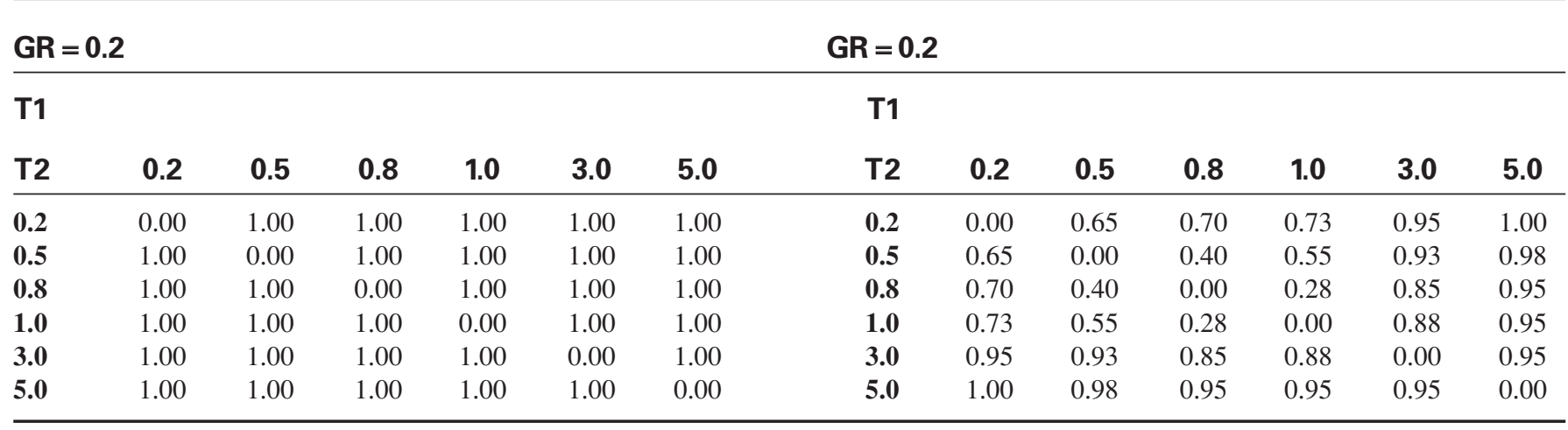

$\mathrm{GR}=\mathbf{0 . 5}$

T1

\begin{tabular}{ccccccc} 
T2 & $\mathbf{0 . 2}$ & $\mathbf{0 . 5}$ & $\mathbf{0 . 8}$ & $\mathbf{1 . 0}$ & $\mathbf{3 . 0}$ & $\mathbf{5 . 0}$ \\
\hline $\mathbf{0 . 2}$ & 0.00 & 1.00 & 1.00 & 1.00 & 1.00 & 1.00 \\
$\mathbf{0 . 5}$ & 1.00 & 0.00 & 0.98 & 0.98 & 1.00 & 1.00 \\
$\mathbf{0 . 8}$ & 1.00 & 0.98 & 0.00 & 0.95 & 1.00 & 1.00 \\
$\mathbf{1 . 0}$ & 1.00 & 0.98 & 0.95 & 0.00 & 0.98 & 0.98 \\
$\mathbf{3 . 0}$ & 1.00 & 1.00 & 1.00 & 0.98 & 0.00 & 0.9 \\
$\mathbf{5 . 0}$ & 1.00 & 1.00 & 1.00 & 0.98 & 0.95 & 0.00
\end{tabular}

$\mathbf{G R}=\mathbf{0 . 8}$

\section{T1}

T2

\begin{tabular}{lllllll}
\hline $\mathbf{0 . 2}$ & 0.00 & 0.68 & 0.85 & 0.80 & 0.98 & 0.85 \\
$\mathbf{0 . 5}$ & 0.68 & 0.00 & 0.20 & 0.35 & 0.80 & 0.83 \\
$\mathbf{0 . 8}$ & 0.85 & 0.20 & 0.00 & 0.00 & 0.53 & 0.73 \\
$\mathbf{1 . 0}$ & 0.80 & 0.35 & 0.00 & 0.00 & 0.43 & 0.50 \\
$\mathbf{3 . 0}$ & 0.98 & 0.80 & 0.53 & 0.43 & 0.00 & 0.25 \\
$\mathbf{5 . 0}$ & 0.85 & 0.83 & 0.73 & 0.50 & 0.25 & 0.00
\end{tabular}

$\mathrm{GR}=\mathbf{0 . 8}$

$\mathrm{GR}=0.5$
T1

$\begin{array}{lllllll}\text { T2 } & \mathbf{0 . 2} & \mathbf{0 . 5} & \mathbf{0 . 8} & \mathbf{1 . 0} & \mathbf{3 . 0} & \mathbf{5 . 0} \\ \mathbf{0 . 2} & 0.00 & 0.08 & 0.25 & 0.38 & 0.63 & 0.88 \\ \mathbf{0 . 5} & 0.08 & 0.00 & 0.10 & 0.20 & 0.48 & 0.78 \\ \mathbf{0 . 8} & 0.25 & 0.10 & 0.00 & 0.00 & 0.48 & 0.68 \\ \mathbf{1 . 0} & 0.38 & 0.20 & 0.00 & 0.00 & 0.43 & 0.63 \\ \mathbf{3 . 0} & 0.63 & 0.48 & 0.48 & 0.43 & 0.00 & 0.50 \\ \mathbf{5 . 0} & 0.88 & 0.78 & 0.68 & 0.63 & 0.50 & 0.00\end{array}$

$\mathbf{G R}=0.9$

T1

\begin{tabular}{llllllll} 
T2 & $\mathbf{0 . 2}$ & $\mathbf{0 . 5}$ & $\mathbf{0 . 8}$ & $\mathbf{1 . 0}$ & $\mathbf{3 . 0}$ & $\mathbf{5 . 0}$ & T. \\
\hline $\mathbf{0 . 2}$ & 0.00 & 0.13 & 0.48 & 0.50 & 0.75 & 0.73 & \\
$\mathbf{0 . 5}$ & 0.13 & 0.00 & 0.03 & 0.10 & 0.43 & 0.45 & \\
$\mathbf{0 . 8}$ & 0.48 & 0.03 & 0.00 & 0.00 & 0.18 & 0.30 & \\
$\mathbf{1 . 0}$ & 0.50 & 0.10 & 0.00 & 0.00 & 0.13 & 0.23 & \\
$\mathbf{3 . 0}$ & 0.75 & 0.43 & 0.18 & 0.13 & 0.00 & 0.05 & \\
$\mathbf{5 . 0}$ & 0.73 & 0.45 & 0.30 & 0.23 & 0.05 & 0.00 & \\
\hline
\end{tabular}


Determining the likelihood of at least one impact is important in design, because it can lead to an increase of displacement and thus, potential damage, as well as indicating the likelihood of the additional damage due to impact. Considering inelastic columns significantly decreases this probability compared to the linear case. Finally, note that e was not considered since the measure is only of the risk of impact. Finally, this analysis could be generalized to size gaps if no impact was desired for a design level event.

\subsection{Displacement DCF Spectral Analysis}

Tables 2 and 3 show the linear and nonlinear DCF results, respectively. The left column is the median or $50^{\text {th }}$ percentile DCF and the right column is the $90^{\text {th }}$ percentile results. As noted, all results are for Oscillator 1 and the transpose of these matrices would give the results for Oscillator 2.

In both tables, values are 0 when $T_{1}=T_{2}$, and greater DCF values tend to occur when the periods of Oscillators 1 and 2 differ greatly. Finally, a positive median value of displacement change for one oscillator is typically associated with a negative or very low positive value for the other oscillator, which can be seen by comparing the transpose element in the tables for Oscillator 1 to see the value for Oscillator 2. This outcome reflects the result of momentum/energy transfer.

The probability of impact decreases when GR increases in Table 1 , and increases when $T_{1}$ is very different from $\mathrm{T}_{2}$. Thus, median values tend to zero as the GR increases and can become relatively large for a $T_{1}$ very different from $T_{2}$. For example, for $\mathrm{T}_{1}=5 \mathrm{~s}, \mathrm{~T}_{2}=0.2 \mathrm{~s}, \mathrm{e}=1.0$ and $\mathrm{GR}=$ 0.2 in the linear case, the spectral displacement of Oscillator 1 when impact is taken into account is 3 times greater than when it stands alone. In addition, as the coefficient of restitution (e) gets larger, the median displacement change increases in most cases, because less energy is dissipated in plastic deformation in the collision. The few, small, contradictions to these trends are most likely the result of the limited number of earthquakes run to make the tables, as not all possibilities may be considered with only 20 earthquakes. The $90^{\text {th }}$ percentile DCF values follow the same trends, but have more DCF values greater than 1.0 since it is a more extreme case, indicating the difference in relative risk defined.

Concerning differences between the linear and non-linear cases, the same trends hold. However, the values are consistently lower than in the linear case and more values are closer to 0 . In the non- linear case, median values for both oscillators are 0 for $\mathrm{GR}=0.8$ and $\mathrm{GR}=0.9$ regardless of the pair of periods. Thus, the displacement changes for gap ratios of 0.8 and 0.9 are not presented in Table 3 as they were zero for all periods in both the $50^{\text {th }}$ and $90^{\text {th }}$ percentiles. This result indicates that for at least $50 \%$ of earthquakes, spectral displacement is the same or lower with and without impact. This result is linked with the very low probability of impact for these two high values of GR (see Table 1). However, it also indicates cases where structural impact does not need to be considered in terms of increased demand, although the impact itself will add some damage.

In summary, trends with variation of e, GR or linearity are fundamentally the same as those for the probability of impact. Large median displacement changes indicate important consequences for one of the oscillators, because for the majority of earthquakes the risk of damage due to impact will be high. Similarly all DCF $>1.0$ values indicate cases where added consideration should be given to these design factors, regardless of the risk level $\left(50^{\text {th }}\right.$ or $90^{\text {th }}$ percentile) defined.

\subsection{Limitations and Implications}

The first and major limitation of the study used is the simplicity of the model used. This study can just be applied to two SDOF structures with the same mass and damping. Different masses would change the seismic load and affect the transfer of momentum and impact loads in Eqns 2 to 3. Similarly, different critical damping ratios would change the diagonal, equal periods, case. However, accounting for these added two factors would significantly expand the scope of analyses and are not likely to change the fundamental trends observed. This factor is especially true given that many adjacent structures that would suffer impact are likely to be more broadly similar than not, and the analysis presented generalizes completely to more extreme cases. Thus, the main goal to ensure a basic analysis of the likelihoods of impact and associated risk of increased displacement demand has been achieved and the approach is generalisable to those cases that are not as well covered.

There is a limitation of simplicity in the SDOF models and periods of $0.2-5.0$ seconds analyzed, although the periods are typical of 3-10 story structures which, in seismic zones with higher design demands, are very typically first mode dominant in response with $90 \%$ to $95 \%$ or more of response in the first mode. Thus, the SDOF analysis is valid in this case for the design analysis and risk assessment presented. Equally, a 
Table 2. Median or $50^{\text {th }}$ (left) and $90^{\text {th }}$ (right) percentile displacement change (elastic columns, $e=(0.4,0.6,0.8$, $1), G R=(0.2,0.5,0.8,0.9), m_{1}=m_{2}=1000 \mathrm{~kg}, \xi=0.05,20$ earthquake records in the middle suite in both direction, $\mathrm{dt}=\mathbf{0 . 0 0 1 s}$ )

\begin{tabular}{|c|c|c|c|c|c|c|c|c|c|c|c|c|c|}
\hline \multicolumn{14}{|c|}{ Oscillator $1:$ Gap ratio $=0.2$ for $50^{\text {th }}$ percentile (left) and $90^{\text {th }}$ percentile (right) } \\
\hline \multicolumn{14}{|c|}{$e=0.4$} \\
\hline T1 & & & & & & & T1 & & & & & & \\
\hline T2 & 0.2 & 0.5 & 0.8 & 1.0 & 3.0 & 5.0 & T2 & 0.2 & 0.5 & 0.8 & 1.0 & 3.0 & 5.0 \\
\hline 0.2 & 0.00 & 0.39 & 0.74 & 0.87 & 0.69 & 1.09 & 0.2 & 0.00 & 1.04 & 1.79 & 2.24 & 2.96 & 3.01 \\
\hline 0.5 & -0.36 & 0.00 & -0.07 & -0.01 & 0.03 & 0.05 & 0.5 & -0.10 & 0.00 & 0.28 & 0.33 & 0.84 & 0.86 \\
\hline 0.8 & -0.32 & -0.20 & 0.00 & -0.02 & -0.07 & 0.00 & 0.8 & -0.15 & 0.04 & 0.00 & 0.07 & 0.46 & 0.55 \\
\hline 1.0 & -0.33 & -0.22 & 0.00 & 0.00 & -0.07 & -0.01 & 1.0 & -0.11 & 0.07 & 0.17 & 0.00 & 0.52 & 0.46 \\
\hline 3.0 & -0.25 & -0.20 & -0.22 & -0.24 & 0.00 & -0.13 & 3.0 & 0.26 & 0.33 & 0.37 & 0.43 & 0.00 & 0.14 \\
\hline 5.0 & 0.15 & 0.12 & 0.26 & 0.27 & 0.19 & 0.00 & 5.0 & 1.45 & 1.64 & 1.69 & 1.58 & 0.65 & 0.00 \\
\hline
\end{tabular}

$\mathbf{e}=\mathbf{0 . 6}$

T1

T1

\begin{tabular}{|c|c|c|c|c|c|c|c|c|c|c|c|c|c|}
\hline T2 & 0.2 & 0.5 & 0.8 & 1.0 & 3.0 & 5.0 & T2 & 0.2 & 0.5 & 0.8 & 1.0 & 3.0 & 5.0 \\
\hline 0.2 & 0.00 & 0.48 & 0.92 & 1.09 & 1.04 & 1.48 & 0.2 & 0.00 & 1.13 & 2.24 & 2.65 & 3.42 & 3.53 \\
\hline 0.5 & -0.37 & 0.00 & -0.07 & -0.01 & 0.04 & 0.10 & 0.5 & -0.08 & 0.00 & 0.40 & 0.47 & 1.00 & 1.06 \\
\hline 0.8 & -0.27 & -0.20 & 0.00 & 0.00 & -0.05 & 0.00 & 0.8 & -0.16 & 0.06 & 0.00 & 0.11 & 0.59 & 0.78 \\
\hline 1.0 & -0.32 & -0.18 & 0.00 & 0.00 & -0.07 & 0.00 & 1.0 & -0.06 & 0.08 & 0.20 & 0.00 & 0.59 & 0.61 \\
\hline 3.0 & -0.21 & -0.14 & -0.16 & -0.15 & 0.00 & -0.13 & 3.0 & 0.49 & 0.46 & 0.51 & 0.68 & 0.00 & 0.19 \\
\hline 5.0 & 0.21 & 0.26 & 0.39 & 0.45 & 0.30 & 0.00 & 5.0 & 2.31 & 1.97 & 1.75 & 1.64 & 0.76 & 0.00 \\
\hline
\end{tabular}

$\mathbf{e}=\mathbf{0 . 8}$

\begin{tabular}{rrrrrrrrrrrrrr} 
T1 & & & & & & \multicolumn{1}{c}{ T1 } & & & & & & \\
T2 & $\mathbf{0 . 2}$ & $\mathbf{0 . 5}$ & \multicolumn{1}{c}{$\mathbf{0 . 8}$} & $\mathbf{1 . 0}$ & $\mathbf{3 . 0}$ & $\mathbf{5 . 0}$ & $\mathbf{T 2}$ & $\mathbf{0 . 2}$ & $\mathbf{0 . 5}$ & $\mathbf{0 . 8}$ & $\mathbf{1 . 0}$ & $\mathbf{3 . 0}$ & $\mathbf{5 . 0}$ \\
\hline $\mathbf{0 . 2}$ & 0.00 & 0.67 & 1.07 & 1.27 & 1.11 & 1.72 & $\mathbf{0 . 2}$ & 0.00 & 1.26 & 2.50 & 3.17 & 3.89 & 3.87 \\
$\mathbf{0 . 5}$ & -0.31 & 0.00 & -0.01 & 0.10 & 0.07 & 0.12 & $\mathbf{0 . 5}$ & -0.08 & 0.00 & 0.53 & 0.65 & 1.27 & 1.34 \\
$\mathbf{0 . 8}$ & -0.26 & -0.19 & 0.00 & 0.00 & -0.02 & 0.02 & $\mathbf{0 . 8}$ & -0.06 & 0.07 & 0.00 & 0.15 & 0.78 & 0.94 \\
$\mathbf{1 . 0}$ & -0.28 & -0.12 & 0.01 & 0.00 & -0.03 & 0.00 & $\mathbf{1 . 0}$ & -0.05 & 0.08 & 0.26 & 0.00 & 0.65 & 0.81 \\
$\mathbf{3 . 0}$ & -0.16 & -0.07 & -0.12 & -0.08 & 0.00 & -0.13 & $\mathbf{3 . 0}$ & 0.59 & 0.62 & 0.71 & 0.65 & 0.00 & 0.27 \\
$\mathbf{5 . 0}$ & 0.24 & 0.39 & 0.67 & 0.58 & 0.42 & 0.00 & $\mathbf{5 . 0}$ & 2.39 & 2.23 & 2.15 & 1.91 & 0.87 & 0.00 \\
\hline
\end{tabular}

$\mathbf{e}=\mathbf{1 . 0}$

\begin{tabular}{rrrrrrrrrrrrrr}
\hline T1 & & & & & & & T1 & & & & & & \\
T2 & $\mathbf{0 . 2}$ & $\mathbf{0 . 5}$ & $\mathbf{0 . 8}$ & $\mathbf{1 . 0}$ & $\mathbf{3 . 0}$ & $\mathbf{5 . 0}$ & $\mathbf{T 2}$ & $\mathbf{0 . 2}$ & $\mathbf{0 . 5}$ & $\mathbf{0 . 8}$ & $\mathbf{1 . 0}$ & $\mathbf{3 . 0}$ & $\mathbf{5 . 0}$ \\
\hline $\mathbf{0 . 2}$ & 0.00 & 0.88 & 1.26 & 1.62 & 1.45 & 2.10 & $\mathbf{0 . 2}$ & 0.00 & 1.48 & 2.73 & 3.75 & 4.59 & 4.81 \\
$\mathbf{0 . 5}$ & -0.28 & 0.00 & 0.10 & 0.17 & 0.14 & 0.22 & $\mathbf{0 . 5}$ & 0.08 & 0.00 & 0.66 & 0.93 & 1.47 & 1.69 \\
$\mathbf{0 . 8}$ & -0.22 & -0.18 & 0.00 & 0.00 & 0.00 & 0.13 & $\mathbf{0 . 8}$ & -0.03 & 0.11 & 0.00 & 0.23 & 0.93 & 1.18 \\
$\mathbf{1 . 0}$ & -0.24 & -0.07 & 0.02 & 0.00 & 0.00 & 0.00 & $\mathbf{1 . 0}$ & 0.11 & 0.14 & 0.35 & 0.00 & 0.72 & 0.95 \\
$\mathbf{3 . 0}$ & -0.14 & 0.00 & 0.00 & 0.00 & 0.00 & -0.12 & $\mathbf{3 . 0}$ & 0.83 & 0.75 & 0.85 & 0.87 & 0.00 & 0.43 \\
$\mathbf{5 . 0}$ & 0.49 & 0.62 & 0.52 & 0.87 & 0.52 & 0.00 & $\mathbf{5 . 0}$ & 2.69 & 2.59 & 2.28 & 2.22 & 1.15 & 0.00 \\
\hline
\end{tabular}

Table 2. (Continued) 
Table 2. Median or $50^{\text {th }}$ (left) and $90^{\text {th }}$ (right) percentile displacement change (elastic columns, $e=(0.4,0.6,0.8$, $1), \mathrm{GR}=(0.2,0.5,0.8,0.9), \mathrm{m}_{1}=\mathrm{m}_{2}=1000 \mathrm{~kg}, \xi=0.05,20$ earthquake records in the middle suite in both direction, $\mathrm{dt}=\mathbf{0 . 0 0 1 \mathrm { s }}$ ) (Continued)

\section{Oscillator 1: Gap ratio $=0.5$ for $50^{\text {th }}$ percentile (left) and $90^{\text {th }}$ percentile (right)}

$$
e=0.4
$$

T1 T1

\begin{tabular}{|c|c|c|c|c|c|c|c|c|c|c|c|c|c|}
\hline T2 & 0.2 & 0.5 & 0.8 & 1.0 & 3.0 & 5.0 & T2 & 0.2 & 0.5 & 0.8 & 1.0 & 3.0 & 5.0 \\
\hline 0.2 & 0.00 & 0.18 & 0.73 & 0.81 & 0.80 & 0.99 & 0.2 & 0.00 & 0.89 & 1.78 & 2.16 & 2.97 & 3.47 \\
\hline 0.5 & -0.18 & 0.00 & 0.00 & 0.00 & 0.00 & 0.00 & 0.5 & 0.00 & 0.00 & 0.02 & 0.30 & 0.71 & 0.64 \\
\hline 0.8 & -0.17 & -0.05 & 0.00 & 0.00 & 0.00 & 0.00 & 0.8 & 0.00 & 0.08 & 0.00 & 0.00 & 0.26 & 0.23 \\
\hline 1.0 & -0.16 & -0.07 & 0.00 & 0.00 & 0.00 & 0.00 & 1.0 & 0.04 & 0.12 & 0.19 & 0.00 & 0.32 & 0.15 \\
\hline 3.0 & -0.10 & -0.02 & -0.05 & -0.04 & 0.00 & -0.08 & 3.0 & 0.33 & 0.48 & 0.61 & 0.64 & 0.00 & 0.00 \\
\hline 5.0 & 0.18 & 0.17 & 0.26 & 0.24 & 0.08 & 0.00 & 5.0 & 1.57 & 1.62 & 1.61 & 1.48 & 0.46 & 0.00 \\
\hline
\end{tabular}

\section{$\mathbf{e}=0.6$}

T1 T1

\begin{tabular}{|c|c|c|c|c|c|c|c|c|c|c|c|c|c|}
\hline T2 & 0.2 & 0.5 & 0.8 & 1.0 & 3.0 & 5.0 & T2 & 0.2 & 0.5 & 0.8 & 1.0 & 3.0 & 5.0 \\
\hline 0.2 & 0.00 & 0.32 & 0.90 & 1.09 & 1.00 & 1.19 & 0.2 & 0.00 & 1.07 & 2.16 & 2.66 & 3.63 & 4.48 \\
\hline 0.5 & -0.18 & 0.00 & 0.00 & 0.00 & 0.00 & 0.01 & 0.5 & 0.00 & 0.00 & 0.05 & 0.39 & 0.84 & 0.72 \\
\hline 0.8 & -0.19 & -0.05 & 0.00 & 0.00 & 0.00 & 0.00 & 0.8 & 0.00 & 0.10 & 0.00 & 0.00 & 0.40 & 0.34 \\
\hline 1.0 & -0.16 & -0.07 & 0.00 & 0.00 & 0.00 & 0.00 & 1.0 & 0.08 & 0.16 & 0.23 & 0.00 & 0.44 & 0.29 \\
\hline 3.0 & -0.05 & -0.01 & 0.00 & -0.01 & 0.00 & -0.08 & 3.0 & 0.42 & 0.66 & 0.74 & 0.85 & 0.00 & 0.00 \\
\hline 5.0 & 0.38 & 0.24 & 0.46 & 0.32 & 0.15 & 0.00 & 5.0 & 2.03 & 1.91 & 1.89 & 1.73 & 0.59 & 0.00 \\
\hline
\end{tabular}

$$
\mathrm{e}=\mathbf{0 . 8}
$$

\section{T1}

\section{T1}

\begin{tabular}{rcrrrrrrrrrrrr} 
T2 & $\mathbf{0 . 2}$ & $\mathbf{0 . 5}$ & $\mathbf{0 . 8}$ & $\mathbf{1 . 0}$ & $\mathbf{3 . 0}$ & $\mathbf{5 . 0}$ & $\mathbf{T 2}$ & $\mathbf{0 . 2}$ & $\mathbf{0 . 5}$ & $\mathbf{0 . 8}$ & $\mathbf{1 . 0}$ & $\mathbf{3 . 0}$ & $\mathbf{5 . 0}$ \\
\hline $\mathbf{0 . 2}$ & 0.00 & 0.49 & 1.10 & 1.30 & 1.35 & 1.55 & $\mathbf{0 . 2}$ & 0.00 & 1.28 & 2.54 & 3.09 & 4.36 & 5.44 \\
$\mathbf{0 . 5}$ & -0.18 & 0.00 & 0.00 & 0.00 & 0.00 & 0.11 & $\mathbf{0 . 5}$ & 0.00 & 0.00 & 0.10 & 0.50 & 1.11 & 1.13 \\
$\mathbf{0 . 8}$ & -0.19 & -0.03 & 0.00 & 0.00 & 0.00 & 0.00 & $\mathbf{0 . 8}$ & 0.00 & 0.13 & 0.00 & 0.00 & 0.53 & 0.58 \\
$\mathbf{1 . 0}$ & -0.16 & -0.06 & 0.00 & 0.00 & 0.00 & 0.00 & $\mathbf{1 . 0}$ & 0.08 & 0.21 & 0.27 & 0.00 & 0.57 & 0.52 \\
$\mathbf{3 . 0}$ & -0.01 & 0.01 & 0.05 & 0.00 & 0.00 & -0.06 & $\mathbf{3 . 0}$ & 0.55 & 0.82 & 0.88 & 0.90 & 0.00 & 0.00 \\
$\mathbf{5 . 0}$ & 0.40 & 0.43 & 0.65 & 0.39 & 0.26 & 0.00 & $\mathbf{5 . 0}$ & 2.39 & 2.20 & 2.23 & 1.99 & 0.71 & 0.00 \\
\hline
\end{tabular}

\section{$\mathrm{e}=\mathbf{1 . 0}$}

\begin{tabular}{lrrrrrrrrrrrrr} 
T1 & & & & & & \multicolumn{1}{c}{ T1 } & & & & & & \\
T2 & $\mathbf{0 . 2}$ & $\mathbf{0 . 5}$ & $\mathbf{0 . 8}$ & $\mathbf{1 . 0}$ & $\mathbf{3 . 0}$ & $\mathbf{5 . 0}$ & $\mathbf{T 2}$ & $\mathbf{0 . 2}$ & $\mathbf{0 . 5}$ & $\mathbf{0 . 8}$ & $\mathbf{1 . 0}$ & $\mathbf{3 . 0}$ & $\mathbf{5 . 0}$ \\
\hline $\mathbf{0 . 2}$ & 0.00 & 0.68 & 1.23 & 1.53 & 1.58 & 1.90 & $\mathbf{0 . 2}$ & 0.00 & 1.49 & 2.87 & 3.54 & 5.03 & 6.42 \\
$\mathbf{0 . 5}$ & -0.19 & 0.00 & 0.00 & 0.03 & 0.03 & 0.19 & $\mathbf{0 . 5}$ & 0.00 & 0.00 & 0.22 & 0.61 & 1.38 & 1.64 \\
$\mathbf{0 . 8}$ & -0.18 & -0.02 & 0.00 & 0.00 & 0.00 & 0.00 & $\mathbf{0 . 8}$ & 0.01 & 0.16 & 0.00 & 0.00 & 0.69 & 0.87 \\
$\mathbf{1 . 0}$ & -0.15 & -0.02 & 0.00 & 0.00 & 0.00 & 0.00 & $\mathbf{1 . 0}$ & 0.10 & 0.28 & 0.32 & 0.00 & 0.72 & 0.65 \\
$\mathbf{3 . 0}$ & -0.03 & -0.02 & 0.10 & 0.05 & 0.00 & -0.07 & $\mathbf{3 . 0}$ & 0.46 & 0.98 & 1.11 & 1.12 & 0.00 & 0.02 \\
$\mathbf{5 . 0}$ & 0.59 & 0.63 & 0.68 & 0.46 & 0.39 & 0.00 & $\mathbf{5 . 0}$ & 2.28 & 2.37 & 2.65 & 2.35 & 0.86 & 0.00 \\
\hline
\end{tabular}


Table 2. Median or $50^{\text {th }}$ (left) and $90^{\text {th }}$ (right) percentile displacement change (elastic columns, $e=(0.4,0.6,0.8$, $1), G R=(0.2,0.5,0.8,0.9), m_{1}=m_{2}=1000 \mathrm{~kg}, \xi=0.05,20$ earthquake records in the middle suite in both direction, $\mathrm{dt}=\mathbf{0 . 0 0 1} \mathrm{s})$ (Continued)

\begin{tabular}{|c|c|c|c|c|c|c|c|c|c|c|c|c|c|}
\hline \multicolumn{14}{|c|}{ Oscillator $1:$ Gap ratio $=0.8$ for $50^{\text {th }}$ percentile (left) and $90^{\text {th }}$ percentile (right) } \\
\hline \multicolumn{14}{|c|}{$\mathrm{e}=0.4$} \\
\hline T1 & & & & & & & T1 & & & & & & \\
\hline $\mathrm{T} 2$ & 0.2 & 0.5 & 0.8 & 1.0 & 3.0 & 5.0 & T2 & 0.2 & 0.5 & 0.8 & 1.0 & 3.0 & 5.0 \\
\hline 0.2 & 0.00 & 0.00 & 0.00 & 0.08 & 0.31 & 0.06 & 0.2 & 0.00 & 0.15 & 0.83 & 0.90 & 1.68 & 1.53 \\
\hline 0.5 & 0.00 & 0.00 & 0.00 & 0.00 & 0.00 & 0.00 & 0.5 & 0.00 & 0.00 & 0.00 & 0.00 & 0.09 & 0.00 \\
\hline 0.8 & -0.03 & 0.00 & 0.00 & 0.00 & 0.00 & 0.00 & 0.8 & 0.00 & 0.00 & 0.00 & 0.00 & 0.00 & 0.00 \\
\hline 1.0 & -0.05 & 0.00 & 0.00 & 0.00 & 0.00 & 0.00 & 1.0 & 0.00 & 0.00 & 0.00 & 0.00 & 0.00 & 0.02 \\
\hline 3.0 & -0.03 & -0.01 & 0.00 & 0.00 & 0.00 & 0.00 & 3.0 & 0.21 & 0.18 & 0.32 & 0.11 & 0.00 & 0.00 \\
\hline 5.0 & 0.00 & 0.00 & 0.00 & 0.00 & 0.00 & 0.00 & 5.0 & 0.67 & 1.12 & 1.00 & 0.74 & 0.00 & 0.00 \\
\hline
\end{tabular}

$\mathbf{e}=\mathbf{0 . 6}$

T1

T1

\begin{tabular}{rrrrrrrrrrrrrr} 
T2 & $\mathbf{0 . 2}$ & $\mathbf{0 . 5}$ & $\mathbf{0 . 8}$ & $\mathbf{1 . 0}$ & $\mathbf{3 . 0}$ & $\mathbf{5 . 0}$ & $\mathbf{T 2}$ & $\mathbf{0 . 2}$ & $\mathbf{0 . 5}$ & $\mathbf{0 . 8}$ & $\mathbf{1 . 0}$ & $\mathbf{3 . 0}$ & $\mathbf{5 . 0}$ \\
\hline $\mathbf{0 . 2}$ & 0.00 & 0.00 & 0.03 & 0.18 & 0.45 & 0.22 & $\mathbf{0 . 2}$ & 0.00 & 0.24 & 1.11 & 1.25 & 2.08 & 1.84 \\
$\mathbf{0 . 5}$ & 0.00 & 0.00 & 0.00 & 0.00 & 0.00 & 0.00 & $\mathbf{0 . 5}$ & 0.00 & 0.00 & 0.00 & 0.00 & 0.21 & 0.00 \\
$\mathbf{0 . 8}$ & -0.03 & 0.00 & 0.00 & 0.00 & 0.00 & 0.00 & $\mathbf{0 . 8}$ & 0.00 & 0.00 & 0.00 & 0.00 & 0.00 & 0.00 \\
$\mathbf{1 . 0}$ & -0.05 & 0.00 & 0.00 & 0.00 & 0.00 & 0.00 & $\mathbf{1 . 0}$ & 0.01 & 0.00 & 0.00 & 0.00 & 0.00 & 0.04 \\
$\mathbf{3 . 0}$ & -0.02 & 0.00 & 0.00 & 0.00 & 0.00 & 0.00 & $\mathbf{3 . 0}$ & 0.28 & 0.25 & 0.42 & 0.17 & 0.00 & 0.00 \\
$\mathbf{5 . 0}$ & 0.01 & 0.00 & 0.00 & 0.00 & 0.00 & 0.00 & $\mathbf{5 . 0}$ & 0.98 & 1.31 & 1.24 & 0.88 & 0.02 & 0.00 \\
\hline
\end{tabular}

$\mathbf{e}=\mathbf{0 . 8}$

\begin{tabular}{|c|c|c|c|c|c|c|c|c|c|c|c|c|c|}
\hline T1 & & & & & & & T1 & & & & & & \\
\hline T2 & 0.2 & 0.5 & 0.8 & 1.0 & 3.0 & 5.0 & T2 & 0.2 & 0.5 & 0.8 & 1.0 & 3.0 & 5.0 \\
\hline 0.2 & 0.00 & 0.00 & 0.11 & 0.33 & 0.75 & 0.42 & 0.2 & 0.00 & 0.32 & 1.47 & 1.60 & 2.67 & 2.41 \\
\hline 0.5 & 0.00 & 0.00 & 0.00 & 0.00 & 0.00 & 0.00 & 0.5 & 0.00 & 0.00 & 0.00 & 0.00 & 0.33 & 0.06 \\
\hline 0.8 & -0.03 & 0.00 & 0.00 & 0.00 & 0.00 & 0.00 & 0.8 & 0.00 & 0.00 & 0.00 & 0.00 & 0.00 & 0.00 \\
\hline 1.0 & -0.05 & 0.00 & 0.00 & 0.00 & 0.00 & 0.00 & 1.0 & 0.02 & 0.02 & 0.00 & 0.00 & 0.00 & 0.06 \\
\hline 3.0 & -0.01 & 0.00 & 0.00 & 0.00 & 0.00 & 0.00 & 3.0 & 0.29 & 0.32 & 0.51 & 0.23 & 0.00 & 0.00 \\
\hline 5.0 & 0.03 & 0.03 & 0.00 & 0.00 & 0.00 & 0.00 & 5.0 & 1.03 & 1.54 & 1.48 & 1.03 & 0.05 & 0.00 \\
\hline
\end{tabular}

$\mathbf{e}=\mathbf{1 . 0}$

\begin{tabular}{|c|c|c|c|c|c|c|c|c|c|c|c|c|c|}
\hline T1 & & & & & & & T1 & & & & & & \\
\hline T2 & 0.2 & 0.5 & 0.8 & 1.0 & 3.0 & 5.0 & T2 & 0.2 & 0.5 & 0.8 & 1.0 & 3.0 & 5.0 \\
\hline 0.2 & 0.00 & 0.00 & 0.19 & 0.50 & 0.97 & 0.67 & 0.2 & 0.00 & 0.42 & 1.74 & 1.93 & 3.25 & 3.11 \\
\hline 0.5 & 0.00 & 0.00 & 0.00 & 0.00 & 0.00 & 0.00 & 0.5 & 0.00 & 0.00 & 0.00 & 0.00 & 0.48 & 0.24 \\
\hline 0.8 & -0.04 & 0.00 & 0.00 & 0.00 & 0.00 & 0.00 & 0.8 & 0.00 & 0.00 & 0.00 & 0.00 & 0.00 & 0.00 \\
\hline 1.0 & -0.05 & 0.00 & 0.00 & 0.00 & 0.00 & 0.00 & 1.0 & 0.02 & 0.03 & 0.00 & 0.00 & 0.00 & 0.05 \\
\hline 3.0 & -0.02 & 0.00 & 0.00 & 0.00 & 0.00 & 0.00 & 3.0 & 0.29 & 0.39 & 0.61 & 0.29 & 0.00 & 0.00 \\
\hline 5.0 & 0.06 & 0.06 & 0.00 & 0.00 & 0.00 & 0.00 & 5.0 & 1.26 & 1.76 & 1.70 & 1.16 & 0.11 & 0.00 \\
\hline
\end{tabular}

Table 2. (Continued) 
Table 2. Median or $50^{\text {th }}$ (left) and $90^{\text {th }}$ (right) percentile displacement change (elastic columns, $e=(0.4,0.6,0.8$, $1), \mathrm{GR}=(0.2,0.5,0.8,0.9), \mathrm{m}_{1}=\mathrm{m}_{2}=1000 \mathrm{~kg}, \xi=0.05,20$ earthquake records in the middle suite in both direction, $\mathrm{dt}=\mathbf{0 . 0 0 1} \mathrm{s}$ ) (Continued)

\section{Oscillator 1: Gap ratio $=0.9$ for $50^{\text {th }}$ percentile (left) and $90^{\text {th }}$ percentile (right)}

$$
\mathrm{e}=0.4
$$

T1 T1

\begin{tabular}{|c|c|c|c|c|c|c|c|c|c|c|c|c|c|}
\hline T2 & 0.2 & 0.5 & 0.8 & 1.0 & 3.0 & 5.0 & T2 & 0.2 & 0.5 & 0.8 & 1.0 & 3.0 & 5.0 \\
\hline 0.2 & 0.00 & 0.00 & 0.00 & 0.00 & 0.00 & 0.00 & 0.2 & 0.00 & 0.00 & 0.23 & 0.38 & 0.63 & 0.68 \\
\hline 0.5 & 0.00 & 0.00 & 0.00 & 0.00 & 0.00 & 0.00 & 0.5 & 0.00 & 0.00 & 0.00 & 0.00 & 0.00 & 0.00 \\
\hline 0.8 & 0.00 & 0.00 & 0.00 & 0.00 & 0.00 & 0.00 & 0.8 & 0.00 & 0.00 & 0.00 & 0.00 & 0.00 & 0.00 \\
\hline 1.0 & 0.00 & 0.00 & 0.00 & 0.00 & 0.00 & 0.00 & 1.0 & 0.00 & 0.00 & 0.00 & 0.00 & 0.00 & 0.00 \\
\hline 3.0 & 0.00 & 0.00 & 0.00 & 0.00 & 0.00 & 0.00 & 3.0 & 0.06 & 0.09 & 0.01 & 0.00 & 0.00 & 0.00 \\
\hline 5.0 & 0.00 & 0.00 & 0.00 & 0.00 & 0.00 & 0.00 & 5.0 & 0.56 & 0.36 & 0.08 & 0.18 & 0.00 & 0.00 \\
\hline
\end{tabular}

$$
\mathrm{e}=0.6
$$

T1

\begin{tabular}{|c|c|c|c|c|c|c|c|c|c|c|c|c|c|}
\hline T2 & 0.2 & 0.5 & 0.8 & 1.0 & 3.0 & 5.0 & T2 & 0.2 & 0.5 & 0.8 & 1.0 & 3.0 & 5.0 \\
\hline 0.2 & 0.00 & 0.00 & 0.00 & 0.00 & 0.00 & 0.00 & 0.2 & 0.00 & 0.00 & 0.32 & 0.53 & 0.94 & 0.89 \\
\hline 0.5 & 0.00 & 0.00 & 0.00 & 0.00 & 0.00 & 0.00 & 0.5 & 0.00 & 0.00 & 0.00 & 0.00 & 0.00 & 0.00 \\
\hline 0.8 & 0.00 & 0.00 & 0.00 & 0.00 & 0.00 & 0.00 & 0.8 & 0.00 & 0.00 & 0.00 & 0.00 & 0.00 & 0.00 \\
\hline 1.0 & 0.00 & 0.00 & 0.00 & 0.00 & 0.00 & 0.00 & 1.0 & 0.00 & 0.00 & 0.00 & 0.00 & 0.00 & 0.00 \\
\hline 3.0 & 0.00 & 0.00 & 0.00 & 0.00 & 0.00 & 0.00 & 3.0 & 0.07 & 0.14 & 0.04 & 0.00 & 0.00 & 0.00 \\
\hline 5.0 & 0.00 & 0.00 & 0.00 & 0.00 & 0.00 & 0.00 & 5.0 & 0.66 & 0.49 & 0.13 & 0.24 & 0.00 & 0.00 \\
\hline
\end{tabular}

T1

$$
e=0.8
$$

\section{T1}

\begin{tabular}{llllllll} 
T2 & $\mathbf{0 . 2}$ & $\mathbf{0 . 5}$ & $\mathbf{0 . 8}$ & $\mathbf{1 . 0}$ & $\mathbf{3 . 0}$ & $\mathbf{5 . 0}$ & \\
\hline $\mathbf{0 . 2}$ & 0.00 & 0.00 & 0.00 & 0.00 & 0.02 & 0.00 & $\mathbf{0 . 2}$ \\
$\mathbf{0 . 5}$ & 0.00 & 0.00 & 0.00 & 0.00 & 0.00 & 0.00 & $\mathbf{0 . 5}$ \\
$\mathbf{0 . 8}$ & 0.00 & 0.00 & 0.00 & 0.00 & 0.00 & 0.00 & $\mathbf{0 . 0}$ \\
$\mathbf{1 . 0}$ & 0.00 & 0.00 & 0.00 & 0.00 & 0.00 & 0.00 & \\
$\mathbf{3 . 0}$ & 0.00 & 0.00 & 0.00 & 0.00 & 0.00 & 0.00 & \\
$\mathbf{5 . 0}$ & 0.00 & 0.00 & 0.00 & 0.00 & 0.00 & 0.00 & \\
\hline
\end{tabular}

\section{T1}

\begin{tabular}{ccccccc} 
T2 & $\mathbf{0 . 2}$ & $\mathbf{0 . 5}$ & $\mathbf{0 . 8}$ & $\mathbf{1 . 0}$ & $\mathbf{3 . 0}$ & $\mathbf{5 . 0}$ \\
$\mathbf{0 . 2}$ & 0.00 & 0.00 & 0.42 & 0.67 & 1.25 & 1.10 \\
$\mathbf{0 . 5}$ & 0.00 & 0.00 & 0.00 & 0.00 & 0.00 & 0.00 \\
$\mathbf{0 . 8}$ & 0.00 & 0.00 & 0.00 & 0.00 & 0.00 & 0.00 \\
$\mathbf{1}$ & 0.00 & 0.00 & 0.00 & 0.00 & 0.00 & 0.00 \\
$\mathbf{3}$ & 0.11 & 0.19 & 0.08 & 0.00 & 0.00 & 0.00 \\
$\mathbf{5}$ & 0.78 & 0.62 & 0.19 & 0.31 & 0.00 & 0.00 \\
\hline
\end{tabular}

$e=1.0$

T1

T1

\begin{tabular}{llllllllllllll} 
T2 & $\mathbf{0 . 2}$ & $\mathbf{0 . 5}$ & $\mathbf{0 . 8}$ & $\mathbf{1 . 0}$ & $\mathbf{3 . 0}$ & $\mathbf{5 . 0}$ & $\mathbf{T 2}$ & $\mathbf{0 . 2}$ & $\mathbf{0 . 5}$ & $\mathbf{0 . 8}$ & $\mathbf{1 . 0}$ & $\mathbf{3 . 0}$ & $\mathbf{5 . 0}$ \\
\hline $\mathbf{0 . 2}$ & 0.00 & 0.00 & 0.00 & 0.00 & 0.13 & 0.00 & $\mathbf{0 . 2}$ & 0.00 & 0.00 & 0.52 & 0.82 & 1.57 & 1.35 \\
$\mathbf{0 . 5}$ & 0.00 & 0.00 & 0.00 & 0.00 & 0.00 & 0.00 & $\mathbf{0 . 5}$ & 0.00 & 0.00 & 0.00 & 0.00 & 0.00 & 0.00 \\
$\mathbf{0 . 8}$ & 0.00 & 0.00 & 0.00 & 0.00 & 0.00 & 0.00 & $\mathbf{0 . 8}$ & 0.00 & 0.00 & 0.00 & 0.00 & 0.00 & 0.00 \\
$\mathbf{1 . 0}$ & 0.00 & 0.00 & 0.00 & 0.00 & 0.00 & 0.00 & $\mathbf{1 . 0}$ & 0.00 & 0.00 & 0.00 & 0.00 & 0.00 & 0.00 \\
$\mathbf{3 . 0}$ & 0.00 & 0.00 & 0.00 & 0.00 & 0.00 & 0.00 & $\mathbf{3 . 0}$ & 0.13 & 0.23 & 0.11 & 0.00 & 0.00 & 0.00 \\
$\mathbf{5 . 0}$ & 0.00 & 0.00 & 0.00 & 0.00 & 0.00 & 0.00 & $\mathbf{5 . 0}$ & 0.90 & 0.74 & 0.25 & 0.41 & 0.00 & 0.00 \\
\hline
\end{tabular}


Table 3. Median or $50^{\text {th }}$ (left) and $90^{\text {th }}$ (right) percentile displacement change

(inelastic columns, $e=(0.4,1.0), G R=(0.2,0.5), m_{1}=m_{2}=1000 \mathrm{~kg}, \xi=0.05,20$

earthquake records in the middle suite in both direction, $\mathrm{dt}=0.001 \mathrm{~s}$ )

\begin{tabular}{|c|c|c|c|c|c|c|c|c|c|c|c|c|c|}
\hline \multicolumn{14}{|c|}{$e=0.4$} \\
\hline T1 & & & & & & & T1 & & & & & & \\
\hline T2 & 0.2 & 0.5 & 0.8 & 1.0 & 3.0 & 5.0 & T2 & 0.2 & 0.5 & 0.8 & 1.0 & 3.0 & 5.0 \\
\hline 0.2 & 0.00 & 0.00 & 0.00 & 0.00 & 0.49 & 0.50 & 0.2 & 0.00 & 0.22 & 0.62 & 0.63 & 1.62 & 3.17 \\
\hline 0.5 & 0.00 & 0.00 & 0.00 & 0.00 & 0.18 & 0.31 & 0.5 & 0.12 & 0.00 & 0.09 & 0.21 & 1.16 & 1.93 \\
\hline 0.8 & 0.00 & 0.00 & 0.00 & 0.00 & 0.00 & 0.13 & 0.8 & 0.08 & 0.00 & 0.00 & 0.00 & 0.79 & 1.14 \\
\hline 1.0 & 0.00 & 0.00 & 0.00 & 0.00 & 0.00 & 0.01 & 1.0 & 0.19 & 0.00 & 0.00 & 0.00 & 0.59 & 0.70 \\
\hline 3.0 & -0.02 & -0.07 & -0.01 & -0.01 & 0.00 & 0.00 & 3.0 & 0.55 & 0.31 & 0.17 & 0.16 & 0.00 & 0.27 \\
\hline 5.0 & 0.04 & 0.00 & 0.00 & 0.00 & 0.00 & 0.00 & 5.0 & 0.52 & 0.48 & 0.39 & 0.42 & 0.40 & 0.00 \\
\hline
\end{tabular}

$\mathbf{e}=\mathbf{1 . 0}$

\begin{tabular}{|c|c|c|c|c|c|c|c|c|c|c|c|c|c|}
\hline T1 & & & & & & & T1 & & & & & & \\
\hline T2 & 0.2 & 0.5 & 0.8 & 1.0 & 3.0 & 5.0 & T2 & 0.2 & 0.5 & 0.8 & 1.0 & 3.0 & 5.0 \\
\hline 0.2 & 0.00 & 0.00 & 0.00 & 0.00 & 0.78 & 1.05 & 0.2 & 0.00 & 0.32 & 0.82 & 0.89 & 2.82 & 4.44 \\
\hline 0.5 & 0.00 & 0.00 & 0.00 & 0.00 & 0.30 & 0.78 & 0.5 & 0.21 & 0.00 & 0.27 & 0.33 & 1.83 & 3.02 \\
\hline 0.8 & 0.00 & 0.00 & 0.00 & 0.00 & 0.00 & 0.35 & 0.8 & 0.12 & 0.00 & 0.00 & 0.00 & 1.25 & 1.81 \\
\hline 1.0 & 0.00 & 0.00 & 0.00 & 0.00 & 0.00 & 0.30 & 1.0 & 0.30 & 0.00 & 0.00 & 0.00 & 0.87 & 1.46 \\
\hline 3.0 & 0.00 & -0.01 & -0.02 & 0.00 & 0.00 & 0.00 & 3.0 & 0.79 & 0.51 & 0.24 & 0.20 & 0.00 & 0.40 \\
\hline 5.0 & 0.09 & 0.06 & 0.10 & 0.08 & 0.08 & 0.00 & 5.0 & 0.92 & 0.71 & 0.68 & 0.73 & 0.61 & 0.00 \\
\hline
\end{tabular}

Oscillator 1 : Gap ratio $=0.5$, for $50^{\text {th }}$ percentile (left) and $90^{\text {th }}$ percentile (right)

$\mathbf{e}=\mathbf{0 . 4}$

\begin{tabular}{|c|c|c|c|c|c|c|c|c|c|c|c|c|c|}
\hline T1 & & & & & & & T1 & & & & & & \\
\hline T2 & 0.2 & 0.5 & 0.8 & 1.0 & 3.0 & 5.0 & T2 & 0.2 & 0.5 & 0.8 & 1.0 & 3.0 & 5.0 \\
\hline 0.2 & 0.00 & 0.00 & 0.00 & 0.00 & 0.00 & 0.15 & 0.2 & 0.00 & 0.00 & 0.20 & 0.18 & 0.94 & 1.35 \\
\hline 0.5 & 0.00 & 0.00 & 0.00 & 0.00 & 0.00 & 0.00 & 0.5 & 0.00 & 0.00 & 0.00 & 0.00 & 0.44 & 0.62 \\
\hline 0.8 & 0.00 & 0.00 & 0.00 & 0.00 & 0.00 & 0.00 & 0.8 & 0.00 & 0.00 & 0.00 & 0.00 & 0.15 & 0.28 \\
\hline 1.0 & 0.00 & 0.00 & 0.00 & 0.00 & 0.00 & 0.00 & 1.0 & 0.00 & 0.00 & 0.00 & 0.00 & 0.14 & 0.20 \\
\hline 3.0 & 0.00 & 0.00 & 0.00 & 0.00 & 0.00 & 0.00 & 3.0 & 0.07 & 0.00 & 0.00 & 0.00 & 0.00 & 0.00 \\
\hline 5.0 & 0.00 & 0.00 & 0.00 & 0.00 & 0.00 & 0.00 & 5.0 & 0.60 & 0.49 & 0.33 & 0.29 & 0.09 & 0.00 \\
\hline
\end{tabular}

$\mathbf{e}=\mathbf{1 . 0}$

T1

T1

\begin{tabular}{|c|c|c|c|c|c|c|c|c|c|c|c|c|c|}
\hline T2 & 0.2 & 0.5 & 0.8 & 1.0 & 3.0 & 5.0 & T2 & 0.2 & 0.5 & 0.8 & 1.0 & 3.0 & 5.0 \\
\hline 0.2 & 0.00 & 0.00 & 0.00 & 0.00 & 0.00 & 0.41 & 0.2 & 0.00 & 0.00 & 0.35 & 0.38 & 1.36 & 2.14 \\
\hline 0.5 & 0.00 & 0.00 & 0.00 & 0.00 & 0.00 & 0.00 & 0.5 & 0.00 & 0.00 & 0.00 & 0.00 & 0.83 & 1.47 \\
\hline 0.8 & 0.00 & 0.00 & 0.00 & 0.00 & 0.00 & 0.00 & 0.8 & 0.00 & 0.00 & 0.00 & 0.00 & 0.37 & 0.65 \\
\hline 1.0 & 0.00 & 0.00 & 0.00 & 0.00 & 0.00 & 0.00 & 1.0 & 0.00 & 0.00 & 0.00 & 0.00 & 0.21 & 0.50 \\
\hline 3.0 & 0.00 & 0.00 & 0.00 & 0.00 & 0.00 & 0.00 & 3.0 & 0.28 & 0.03 & 0.00 & 0.00 & 0.00 & 0.00 \\
\hline 5.0 & 0.04 & 0.00 & 0.00 & 0.00 & 0.00 & 0.00 & 5.0 & 0.89 & 0.75 & 0.48 & 0.48 & 0.24 & 0.00 \\
\hline
\end{tabular}


SDOF analysis can provide the risks and probabilities presented in a general fashion that a multi-DOF specific structural case cannot, and it is these probabilities that are used in design, and initial analysis and scoping, in a typical performance based design approach. Importantly, no analysis can completely cover all possible configurations and modal response possibilities, so this approach was chosen to describe and reasonably define the probabilities and risks.

The displacement limit was chosen as a percent increase versus the standalone case. This choice was made since it is assumed a standalone design would meet all design level event criteria. The risk levels of $50 \%$ and $90 \%$ likelihood were chosen arbitrarily, but fit in well with performance based design approaches, and the differing weighting that might be applied given the value of the structure.

In addition, seismic acceleration at the base of the structures is assumed to be uniform, which is not necessarily true, for example, with very long bridges, or in any other case that involves long distances. However, most impact problems concern dense areas where the span between structures is relatively small. Therefore, this hypothesis is realistic for many typical cases.

In addition, in this analysis, only floor-to-floor collisions are considered. However, other forms of collision (floor-to-column) are very specific and would require one-off analysis. Such analyses would have dramatically increased the scope of this study and were not its main aim, which was to demonstrate the overall design trends as a general guideline and design tool, rather than a more limited specific design analysis.

More specifically, for designers in particular, this analysis was undertaken for a wide range of values for GR and e to show the general trends. These results should generalize the overall analysis to a far broader range of structures and systems. Thus, the main outcomes of this study have demonstrated those trends, as well as creating a template for analysing such situations generally. Hence, regardless of choices or assumptions the general trends should hold, and thus their implications on designing solutions to manage or avoid impact.

\section{CONCLUSIONS}

This study was conducted to analyze structural impact and responses of two structures, considering a range of design factors including structural gap, coefficient of restitution and the linearity of the structural response. The end outcome was to provide a spectral analysis over all these factors to outline the main trends in seismic response in these situations. The main outcomes include:
- The probability of impact between structures increases as the gap ratio decreases and structural period differences increase.

- The same general behavior with respect to gap ratio was observed for the risk of increasing displacement (DCF > 0.0) due to impact. An increase in the coefficient of restitution, greater linearity, also leads to an increase of the risk of increasing displacement. Those cases with increased displacement indicate cases where there is increased risk of damage due to increased displacement demand, as a result of impact, which does not consider the added damage due to the impact itself. Hence, these cases are the most at risk of significant added damage.

- A non-linear model leads to a drop in both probability of impact and the risk of increasing displacement (DCF $>0.0$ and DCF $>1.0$ occur less). Thus, the use of inelastic columns by design is an option to reduce potential damage to structures, although it carries its own added costs and risks.

- The analysis presented is general and thus provides a template for assessing these systems.

Because the approach is fully generalisable, additional studies can be used to extend the model to more realistic cases, such as adding degrees of freedom or considering more extreme cases including different mass or structural damping values.

\section{REFERENCES}

Anagnostopoulos, S. (1988). "Pounding of buildings in series during earthquakes", Earthquake Engineering \& Structural Dynamics, Vol. 16, No. 3, pp. 443-456.

Chau, K.T. and Wei, X.X. (2001). "Pounding of structures modelled as non-linear impacts of two oscillators", Earthquake Engineering \& Structural Dynamics, Vol. 30, No. 5, pp. 633-651.

Chau, K.T., Wei, X.X., Guo, X. and Shen, C.Y. (2003). "Experimental and theoretical simulations of seismic poundings between two adjacent structures", Earthquake Engineering \& Structural Dynamics, Vol. 32, No. 4, pp. 537-554.

Chopra, A.K. (1995). Dynamics of Structures: Theory and Applications to Earthquake Engineering, Punitharuban Thirugnanasammandamoorthi, USA.

Cole, G., Dhakal, R., Carr, A. and Bull, D. (2011). “An investigation of the effects of mass distribution on pounding structures", Earthquake Engineering \& Structural Dynamics, Vol. 40, No. 6, pp. 641-659.

Conoscente, J., Hamburger, R.O. and Johnson, J.J. (1992). "Dynamic analysis of impacting structural systems", Proceedings of the Tenth World Conference on Earthquake Engineering, Madrid, Spain. 
Goldsmith, W. (2002). Impact : the Theory and Physical behaviour of Colliding Solids, Dover Publications, Mineola, N.Y., USA.

Jankowski, R. (2005). "Non-linear viscoelastic modelling of earthquake-induced structural pounding", Earthquake Engineering \& Structural Dynamics, Vol. 34, No. 6, pp. 595-611.

Jankowski, R. (2006). "Pounding force response spectrum under earthquake excitation”, Engineering Structures, Vol. 28, No. 8, pp. 1149-1161.

Jankowski, R. (2007a). “Assessment of damage due to earthquakeinduced pounding between the main building and the stairway tower", Key Engineering Materials, Vol. 347, pp. 339-344.

Jankowski, R. (2007b). "Theoretical and experimental assessment of parameters for the non-linear viscoelastic model of structural pounding", Journal of Theoretical and Applied Mechanics, Vol. 45, No. 4, pp. 931-942.

Jankowski, R. (2010). "Experimental study on earthquake-induced pounding between structural elements made of different building materials", Earthquake Engineering \& Structural Dynamics, Vol. 39, No. 3, pp. 343-354.

Jankowski, R. (2012). "Non-linear FEM analysis of poundinginvolved response of buildings under non-uniform earthquake excitation", Engineering Structures, Vol. 37, pp. 99-105.

Jankowski, R., Wilde, K. and Fujino, Y. (2000). "Reduction of pounding effects in elevated bridges during earthquakes", Earthquake Engineering \& Structural Dynamics, Vol. 29, No. 2, pp. 195-212.

Kasai, K. and Maison, B.F. (1997). "Building pounding damage during the 1989 Loma Prieta earthquake", Engineering Structures, Vol. 19, No. 3, pp. 195-207.

Lig, B., Chan, K., Chouw, N. and Butterworth, J.W. (2010). "Seismic response of two span scale bridge model due to nonuniform ground excitation and varying subsoil conditions", NZSEE Conference, Wellington, New Zealand.

Lin, J. and Weng, C.C. (2001). "Probability analysis of seismic pounding of adjacent buildings", Earthquake Engineering \& Structural Dynamics, Vol. 30, No. 10, pp. 1539-1557.

Lin, J. and Weng, C.C. (2002). "A study on seismic pounding probability of buildings in Taipei metropolitan area", Chinese Institute of Engineers, Vol. 25, No. 2, pp. 123-135.

Mahmoud, S., Abd-Elhamed, A. and Jankowski, R. (2013). "Earthquake-induced pounding between equal height multistorey buildings considering soil-structure interaction", Bulletin of Earthquake Engineering, Vol. 11, No. 4, pp. 1021-1048.

Maison, B. and Kasai, K (1990). "Analysis for type of structural pounding”, Journal of Structural Engineering, ASCE, Vol. 116, pp. 957-977.

Muthukumar, S. and DesRoches, R. (2006). "A Hertz contact model with non-linear damping for pounding simulation", Earthquake Engineering \& Structural Dynamics, Vol. 35, pp. 811-828.
Pantelidesa, C. and Mab, Z. (1998). "Linear and nonlinear pounding of structural systems", Computers \& Structures, Vol. 66, pp. 79-92.

Papadrakakis, M., Mouzakis, H. Plevris, N. and Bitzarar, S. (1991). "A Lagrange multiplier solution method for pounding of buildings during earthquakes", Earthquake Engineering \& Structural Dynamics, Vol. 20, pp. 981-998.

Raheem, S.E.A. (2006). "Seismic pounding between adjacent building structures", Electron Journal of Structural Engineering, Vol. 6, pp. 66-74.

Raheem, S.E.A. (2009). "Pounding mitigation and unseating prevention at expansion joints of isolated multi-span bridges", Engineering Structures, Vol. 31, No. 10, pp. 2345-2356.

Raheem, S.E.A. (2014). "Mitigation measures for earthquake induced pounding effects on seismic performance of adjacent buildings", Bulletin of Earthquake Engineering, Vol. 12, No. 4, pp. 1705-1724.

Ramberg, W. and Osgood, W.R. (1943). "Description of stressstrain curves by three parameters", Technical Note No. 902, National Advisory Committee on Aeronautics, Washington, D.C., USA.

Rosenblueth, E. and Meli, R. (1986). "The 1985 earthquake: causes and effects in Mexico City", Concrete International, American Concrete Institute, Vol. 5, pp. 23-24.

Scholl, R. (1989). "Observations of the performance of buildings during the 1985 Mexico earthquake, and structural design implications", International Journal of Mining and Geological Engineering, Vol. 7, pp. 69-99.

Sommerville, P., Smith, N., Punyamurthula, S. and Sun, J. (1997). "Development of ground motion time histories for phase II of the FEMA/SAC steel project", SAC Background Document Report, SAC/BD-97/04, USA.

Trochalakis, P., Eberhard, M.O. and Stanton, J.F. (1997). "Design of seismic restrainers for in-span hinges", Journal of Structural Engineering, ASCE, Vol. 123, pp. 469-478.

Ye, K., Li, L. and Zhu, H. (2009). "A note on the Hertz contact model with nonlinear damping for pounding simulation", Earthquake Engineering \& Structural Dynamics, Vol. 38, pp. $1135-1142$.

\section{APPENDIX 1}

A brief $o$ of the derivation of Eqn 2 from (Goldsmith 2002):

Using conservation of momentum and noting that that relative velocities just before and after collision are the same (or modified by e if not perfectly elastic), then one can derive as follows:

Conservation of Momentum before impact, at impact, and after impact yields:

$$
\mathrm{m}_{1} \mathrm{x}_{1}+\mathrm{m}_{2} \dot{\mathrm{x}}_{2}=\left(\mathrm{m}_{1}+\mathrm{m}_{2}\right) \dot{\mathrm{x}}_{\mathrm{n}}=\mathrm{m}_{1} \mathrm{x} \dot{\phi}_{1}+\mathrm{m}_{2} \dot{\mathrm{x}}_{2}^{\prime}
$$


The changes in momentum before impact and to impact, $\mathrm{P} 1$, and from impact until after impact, P2, are, conserving momentum, defined:

$$
\begin{gathered}
P 1=\mathrm{m}_{1}\left(\dot{\mathrm{x}}_{1}-\dot{\mathrm{x}}_{n}\right)=\left(\dot{\mathrm{x}}_{n}-\dot{\mathrm{x}}_{2}\right) \\
P 2=\mathrm{m}_{1}\left(\dot{\mathrm{x}}_{\mathrm{n}}-\dot{\mathrm{x}}_{n}^{\prime}\right)=\mathrm{m}_{2}\left(\dot{\mathrm{x}}_{2}^{\prime}-\dot{\mathrm{x}}_{n}\right)
\end{gathered}
$$

Then noting the definition of the coefficient of impact, $e$, one gets:

$$
\dot{\mathrm{x}}_{2}^{\prime}-\dot{\mathrm{x}}_{1}^{\prime}=e\left(\dot{\mathrm{x}}_{1}-\dot{\mathrm{x}}_{2}\right)
$$

Combining Eqns A1-A3 and solving for the velocities after impact yields Eqn 2 in the text, defined:

$$
\begin{aligned}
& \dot{\mathrm{x}}_{1}^{\prime}=\dot{\mathrm{x}}_{1}-(1+\mathrm{e}) \frac{\mathrm{m}_{2}}{\mathrm{~m}_{1}+\mathrm{m}_{2}}\left(\dot{\mathrm{x}}_{1}-\dot{\mathrm{x}}_{2}\right) \\
& \dot{\mathrm{x}}_{2}=\dot{\mathrm{x}}_{2}-(1+\mathrm{e}) \frac{\mathrm{m}_{1}}{\mathrm{~m}_{1}+\mathrm{m}_{2}}\left(\dot{\mathrm{x}}_{1}-\dot{\mathrm{x}}_{2}\right)
\end{aligned}
$$


